\title{
A CROSS SECTIONAL ANTHROPO-CLINICAL STUDY ON ANTIMICROBIALS PRESCRIPTION PATTERN IN GOAT PATIENTS AT CHITTAGONG, BANGLADESH
}

\author{
P. Bhowmik, M. Ahaduzzaman* and R. B. Hasan \\ Department of Medicine \& Surgery, Chittagong Veterinary \& Animal Sciences University, Khulshi-4225, \\ Chittagong, Bangladesh.
}

\begin{abstract}
In the last three decades use of antibiotics in livestock sector has grown tremendously. The uses of these antibiotics have profound impacts on animal health, farmer income and public health. From April, 2016 to March, 2017, a hospital based retrospective study was conducted using clinical record sheet of goat patients $(\mathrm{N}=1405)$ at Teaching Veterinary Hospital (TVH) of Chittagong Veterinary and Animal Sciences University (CVASU), Bangladesh; to assess the groups of antimicrobials used, perception of goat owners' on antibiotics and the annual therapeutic costs for antibiotics that had been used for the treatment of goats at TVH. At TVH, the most prescribed antibiotic was streptomycin-penicillin [437 (31.10\%)], whereas the least used antibiotic was tylosin [7 (0.49\%)]. From anthopo-clinical analysis, only $24 \%$ farmers said they are familiar with the term "antibiotic", but no farmer had any ideas about antimicrobial resistance and its withdrawal period. Considering the average body weight $20-30 \mathrm{~kg}$ of goat patients' we calculated the cost of antibiotic purchase and found the highest money (968.18-1450.04 U.S. Dollars/annum) was expenditure to purchase Gentasone plus ${ }^{\circledR}$ (gentamicine-sulfadiazinetrimithoprime) and the lowest (5.37-8.06 USD/annum) was for tylosin. Ensuring and dissemination of proper knowledge to the farmer regarding antibiotics will prevent them from self purchase and irrational use therefore will help us to reduce the risk of antibiotic resistance in food animal.
\end{abstract}

Keywords: Antibiotic, anthropology, goat patient data, therapeutic cost

\section{INTRODUCTION}

Antimicrobial resistance is one of the most pressing problems faced by healthcare providers in current decades. It is alarming that common bacterial infections are becoming difficult to treat due to antibiotic resistant bacteria. The problem often more focuses in human health sector and poultry industry (Hassan et al., 2014; Allcock et al., 2017), but information on small ruminant, particularly on goat population has not been well studied. Several mechanisms of resistance have been evolved by the bacteria to continue infection, despite use of an antibiotic. Among many, one of the cause has been reported indiscriminate or poor use of antibiotics (Costelloe et al., 2010). Although there are guidelines to reduce the inappropriate uses of antimicrobial but local veterinarians are not implementing these, as a result resistance continues to develop. In Bangladesh it is hard to get a prescription of a goat patient that had been suffered from fever but not treated with any antimicrobial (Sarker et al., 2016). The condition is little differs in human medicine where physicians used to prescribe only antipyretic drug (e.g. paracetamol) rather than any antibiotic to treat a febrile patient (non complicated case) (Sultana et al., 2015). To reduce indiscriminate prescribing of antibiotics in goat medicine, it may therefore be very useful to highlight the effect of antimicrobial use on emergent resistance and implement the standard therapeutic guidelines. A compulsory guidelines for prudent use of antimicrobials in animals was published in Germany in December 2000 (Ungemach et al., 2006). These guidelines describe the minimum requirements need to be followed by veterinarians when administering antibiotics to animals. In high-resource developed countries, an assortment of systems and programs to monitor antibiotic uses, as well as resistance in food animals have been implemented. Such initiatives have led to the substantial decrease of antibiotic consumption and rates of resistance in these settings. However, this yet not been implemented in resource poor settings like Bangladesh.

*Corresponding e-mail address: zaman.cvasu@gmail.com Copyright $(2017$ Bangladesh Society for Veterinary Medicine 


\section{P. Bhowmik and others}

A number of classes of antimicrobials has been registered for veterinary use including the third and fourth generation of cephalosporins, fluoroquinolones and macrolides (Sarmah et al., 2006). Many veterinarians often prescribe these antimicrobials in simple cases to get rapid result (Sarker et al., 2016) without realizing it consequences and development of resistances. Therefore, higher antimicrobials need to be considered as critically important antimicrobials by the veterinarian to cope up with upcoming challenge of resistance. In developing countries prospective like Bangladesh, most common reason for choosing an antimicrobial is personal experience and perception (68\%), rather than the cultural sensitivity test (Akter et al., 2012). It is probably due to unavailability of local vet diagnostic facilities and sometimes unwillingness.

Farmers' knowledge is another important determinant to chase the problem of antibiotic resistance (Friedman et al., 2007). In Chittagong, many goat farmers have primary educational background. Moreover, goat farmers have limited knowledge or concern about the risk of antibiotic resistance. Farmer's perception of efficacy of antimicrobials, based on clinical outcomes, is another important determinant of their preferred choice of product (Vaarst et al., 2002). The 'Antimicrobial Resistance Global Report on Surveillance' by the World Health Organization (WHO) showed high resistance rates in bacterial pathogens frequently implicated in common hospital, community and food chain related infections where there are low level of education (WHO, 2014). Although veterinarians are usually responsible for choosing the appropriate antimicrobials for treatments, choices may also be influenced by farmer's own opinions and needs based on, for example, cost and profit margin, ease of medicine administration and withdrawal period (Van der Fels-Klerx et al., 2011). Therefore, by this hospital based study we tried to find out the prescription pattern of antimicrobials by the vet to treat hospitalized goats', and also analyzed the anthropological information from the goat owners regarding the antimicrobials used at TVH of Chittagong, Bangladesh to reflect the situation of antimicrobial use and its perception among the goat farmers.

\section{MATERIALS AND METHODS}

\section{Study population and design}

Chittagong is a metropolitan city located in south-eastern Bangladesh. Here goat is the primary household livestock rearing by the middle and low income people as an income generating source. Farmers keep their goats in close acquaintance and seldom provide any vaccine. Although, native breeds are less susceptible to infection but imported breed like Jamnapari and their crosses commonly suffer from Peste des Petits Ruminants (PPR), mastitis, pasteurellosis etc. The Teaching Veterinary Hospital (TVH) of Chittagong Veterinary and Animal Sciences University (CVASU) is located at the center of the city and has been providing the healthcare facility among the farmers of Chittagong metropolitan since 1996. Academics of the department of medicine and surgery provide treatment to the patients at TVH. A details data recording sheet has been used to collect epidemiological data, history, clinical findings, diagnosis and treatment. From that data recording sheet we had been collected data of veterinary antimicrobial prescribing patterns at TVH. This cross sectional hospital based retrospective study was performed to determine groups of antimicrobials used in diseased goat admitted to the TVH.

\section{Data collection}

Every day, 20 goat patients (average) come to the TVH. At TVH, every patient's have own clinical record sheet, there included patient's identification, disease history, clinical signs, diagnostic test, prescription and also patient owner address. For our data collection we only used goat patient's clinical record sheet and gathered data on antibiotics used in prescription. Antimicrobials comprised the most diverse group and included three main subgroups: aminoglycoside (gentamicin); $\beta$-lactamase, consisting of amoxicillin, penicillin and ceftriaxone; sulfa drugs including sulfadimidine, sulfadiazine/sulfadimidine/sulfapyridine combination, and sulfanilamide. A combination of penicillin and streptomycin was included as a separate subgroup because of the availability of trade preparation of this combination; oxytetracycline, tylosin, metronidazole, cephalosporin was also recorded. 
The goat owners' brought their goats to the TVH. We also collected information from goat owners' by face-toface contact for recording their knowledge on selective therapeutic parameters such as: antibiotic, antibiotic resistance, withdrawal period, dose completion etc., by using a preplanned questionnaire and subsequently used it to analyze the anthropological data for this study. Only a few cases of goats were brought to the TVH by the servant or neighbor. In that circumstance we did not collect information from them.

At TVH, infectious diseases (bacterial and viral) have been treated with any group of antibiotic to check the primary (bacterial) or secondary infection (viral) for five days. However, treatment periods were more than five days in few cases. Here, we calculated the treatment cost by using the retail market price of each antibiotic and required amount of antibiotic per goat per day. As treatment performed according to the generic dose, therefore we multiplied the amount of antibiotic required (generic dose) per kilogram bodyweight with the animal body weight. In Chittagong, the average body weights of goats are 20-30 kilogram. In cases of combined antibiotic preparation (e.g. bolus of combined sulfur drugs), veterinarian had been followed the trade dose to prescribe, therefore we calculated accordingly.

\section{Data Analysis}

Data were collected in spreadsheets (Excel 2007; Microsoft, Redmond, Washington) and analyzed using statistics software (STAT/IC-13.0), (Stata Corp, 4905, Lakeway Drive, College station, TX 77845, USA). Descriptive statistical analysis was used to measure the means.

\section{RESULTS}

\section{Antimicrobial prescribing pattern}

At the small ruminant unit of SAQTVH, mostly used antibiotic in goat patients was streptomycin-penicillin. 437 patients (31.10\%) were treated with streptomycin-penicillin. The second most prescribed antimicrobial was sulfadimidine, used in total 196 patients (13.95\%). Amoxicillin prescribed in 160 patients (11.39\%). Another combined antimicrobial (gentamicin-sulfadiazine-trimethoprim) used in 130 patients $(9.25 \%)$. Tylosin was the least prescribed antibiotic to goats, used in only 7 patients $(0.48 \%)$ (Table 1 and Figure 1 ).

\section{Therapeutic cost analysis}

We have found the highest expenditure spent by using gentamicine-sulfadiazine-trimithoprime 968.18 USD/annum and then streptomycin-penicillin cost is 352.06 USD /annum whereas the lowest expenditure spent by using tylosin 5.37 USD/annum (Table 1).

Table 1. Frequency of using antibiotic with therapeutic cost from April, 2016 - March, 2017 in goat patients

\begin{tabular}{|c|c|c|c|c|c|c|}
\hline \multirow[t]{2}{*}{ Name of antibiotic } & \multirow[t]{2}{*}{ n/year } & \multirow[t]{2}{*}{$\%$} & \multirow{2}{*}{$\begin{array}{c}\text { Antimicrobial used (ml) } \\
\text { Av. BW=20 to } 30 \mathrm{~kg} \\
\text { (Day } 1)\end{array}$} & \multirow{2}{*}{$\begin{array}{c}\text { Antimicrobial used (ml) } \\
\text { in } 5 \text { therapeutic days } \\
(\text { Day } 1 * 5)\end{array}$} & \multicolumn{2}{|c|}{ Therapeutic cost } \\
\hline & & & & & Taka & $\begin{array}{c}\text { USD } \\
\text { (U.S. dollar) }\end{array}$ \\
\hline Amoxicillin & 160 & 11.39 & $320-480$ & $1600-2400$ & $9600-14400$ & $118.97-178.46$ \\
\hline Ampicillin & 43 & 3.07 & $86-129$ & $430-645$ & $1935-2903$ & $23.98-35.97$ \\
\hline Amoxicillin - Cloxacillin & 37 & 2.63 & 74-111 & $370-555$ & 4884-7326 & $60.52-90.79$ \\
\hline Ciprofloxacin & 38 & 2.70 & $76-114$ & $380-570$ & $1254-1881$ & $15.54-23.31$ \\
\hline Ceftriaxone & 79 & 5.62 & $63-95$ & $315-475$ & $9450-14250$ & $117.11-176.60$ \\
\hline Ceftiofur & 9 & 0.64 & $12-14$ & $60-70$ & $3000-3500$ & $37.17-43.37$ \\
\hline Gentamicin & 31 & 2.21 & $31-47$ & $155-235$ & $574-870$ & 7.11-10.78 \\
\hline Oxytetracycline & 91 & 6.48 & $182-273$ & $910-1365$ & $23660-35490$ & $293.23-439.84$ \\
\hline Penicillin & 103 & 7.33 & $206-309$ & $1030-1545$ & $4635-6953$ & $57.44-86.16$ \\
\hline Streptomycin - Penicillin & 437 & 31.10 & $874-1311$ & $4370-6555$ & $28405-42608$ & $352.06-528.04$ \\
\hline Sulfadimidine & 196 & 13.95 & $1960-2940$ & $9800-14700$ & $9800-14700$ & $121.45-182.18$ \\
\hline Combined sulfur drug & 17 & 1.21 & $20-30$ & $100-150$ & $500-750$ & 6.19-9.29 \\
\hline Gentamicin -sulfadiazine - & & & $260-390$ & $1300-1950$ & 78120 & $968.18-1450.04$ \\
\hline Trimethoprim & 130 & 9.25 & & & -117000 & \\
\hline Tylosin & 7 & 0.50 & $14-21$ & $70-105$ & $434-651$ & $5.37-8.06$ \\
\hline Metronidazole & 27 & 1.92 & $28-42$ & $140-210$ & $700-1050$ & $8.67-13.01$ \\
\hline
\end{tabular}




\section{P. Bhowmik and others}

\section{Anthropological information from farmer about antibiotics}

From anthropological information, we found $100 \%$ owner did not know about antibiotic resistance and withdrawal period of drug, $82 \%$ owner complain that medicine did not work effectively, $75 \%$ owner completed their dose of drug to treat their goat. We also collected information about duration of goat rearing of 100 owners, here minimum duration was 1 month and maximum duration was 180 months and the average duration was 40.91 months (Figure 2).

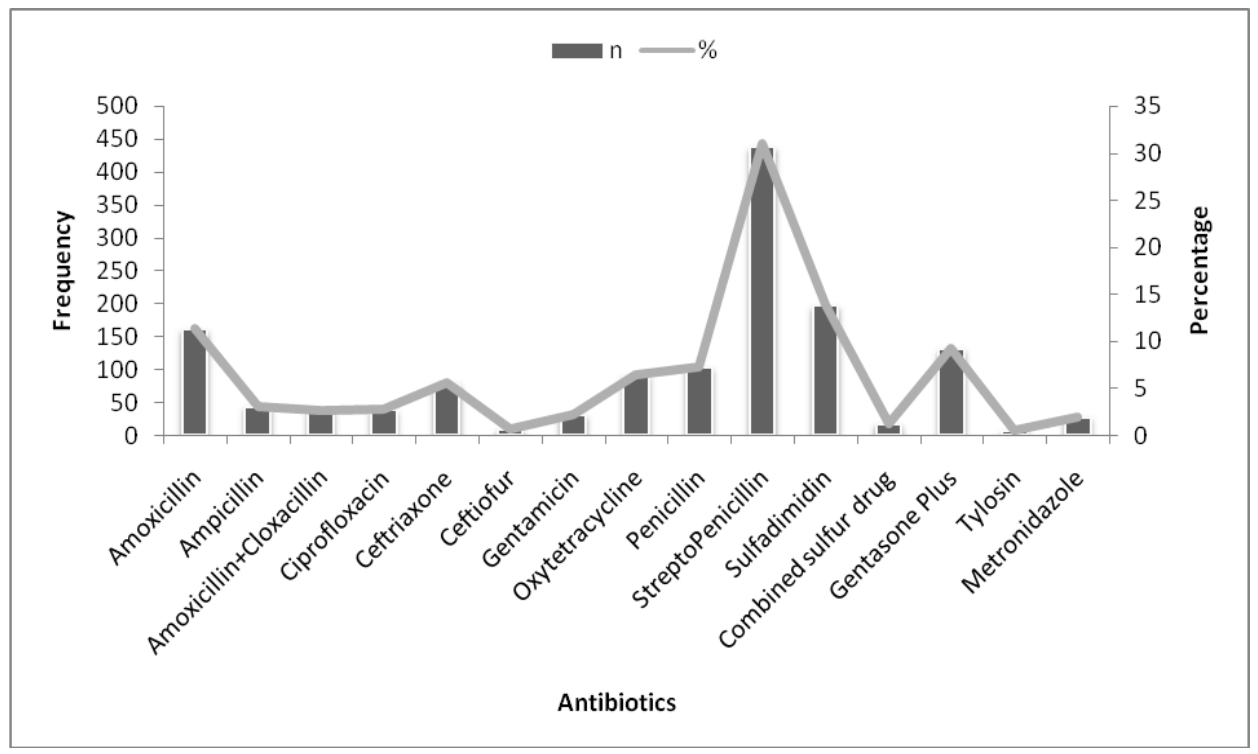

Figure 1. Frequency of antibiotics used in goat patients from April 2016 - March 2017

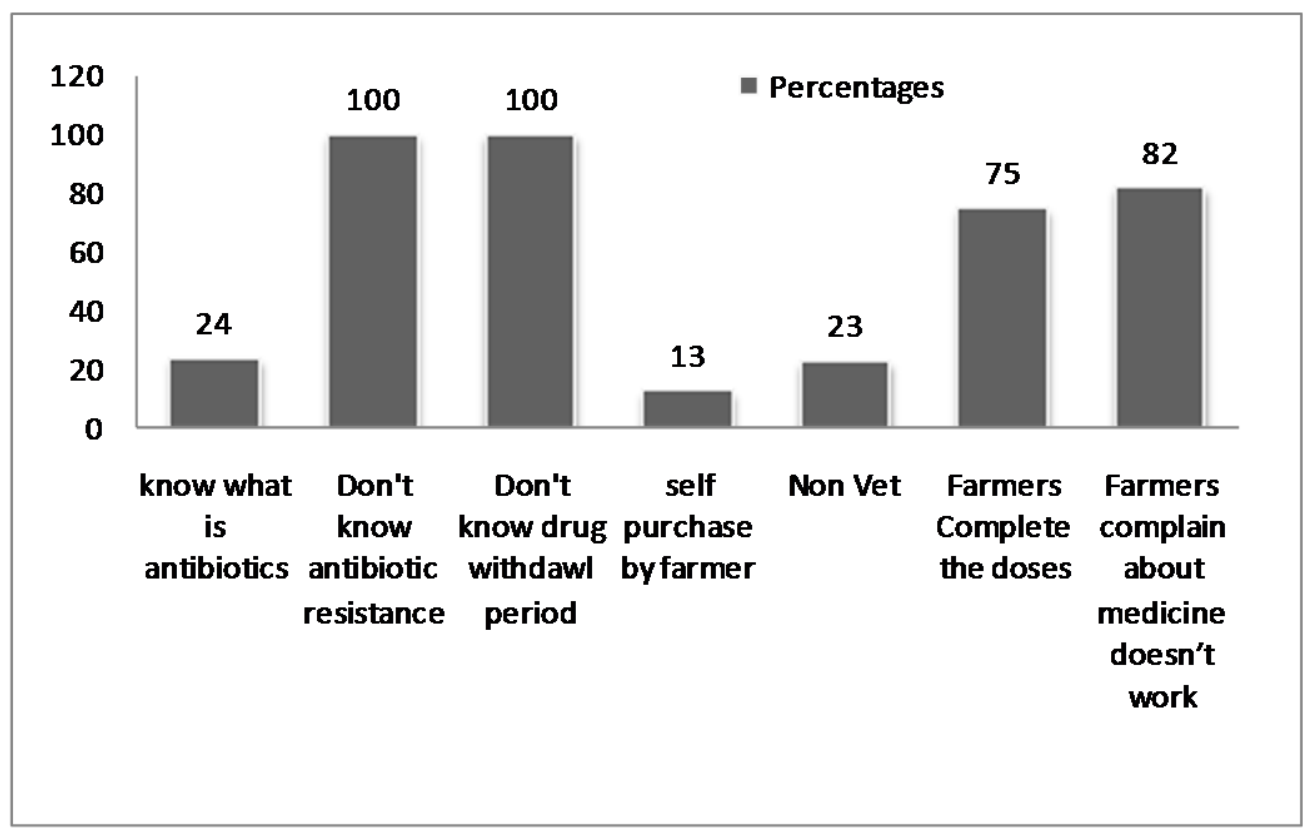

Figure 2. Anthropological information from farmer about antibiotics 


\section{DISCUSSION}

Nowadays, antimicrobial resistance is a global problem. It is a drain on the global economy due to lengthen the therapeutic period and higher costs of treatment. The goal of the global action plan is to ensure successful treatment with effective and safe antimicrobials that are specific and sensitive. It has been estimated the global average annual consumption of antimicrobials per kilogram of animal produced was $45 \mathrm{mg} \cdot \mathrm{kg}^{-1}, 148 \mathrm{mg} \cdot \mathrm{kg}^{-1}$, and $172 \mathrm{mg} \cdot \mathrm{kg}^{-1}$ for cattle, chicken, and pigs, respectively in developed countries (Van Boeckel et al., 2015). The condition is 7 fold more in developing country like India and yet not estimated in Bangladesh.

It was also estimated that $92 \%$ of the total use was for therapeutic purposes (AHI, 2005). However, estimates have varied widely with regard to the relative amounts of antimicrobials used in agriculture. For example, Mathew et al. (2007) reported that 22.7 million $\mathrm{kg}$ of antibiotics produced in the United States of which 17.8\% were used in animal production. In contrast, Mellon et al. (2001) indicated that approximately $70 \%$ of antibiotics produced were used in livestock.

\section{Uses of antibiotics around the globe}

Most antibiotics used in animal production are similar to those used in the human population. Twenty seven antimicrobial classes that are used both in human and animals, only nine are used exclusively in animals (Page and Gautier, 2012). The top three classes by global sales for animal use in 2009 were macrolides ( $\$ 600$ million), penicillins ( $\$ 600$ million), and tetracyclines ( $\$ 500$ million), all of which are categorized as critically important in human medicine (Falzon et al., 2011). Kurwijila et al. (2011) studied antibiotic use by 60 dairy farmers in Morogoro municipality showed the most commonly used antibiotics were penicillin-streptomycin (used by $84 \%$ of farmers), oxytetracycline (used by 60\%) and gentamicin (used by $12 \%$ ), which support our study because we also found most commonly used antibiotic was streptomycin-penicillin(used by $31.10 \%$ of farmers). Midenge (2010) interviewed 187 small scale dairy cattle farmers in Kinondoni Municipality on the type of antibiotics used, they found tetracycline (used by $79.5 \%$ of farmers), penicillin-streptomycin (used by 55\%), sulfadimidine (used by 18\%), gentamycin (used by 10\%) and kanamycin (used by 8\%) were the most common antibiotics used by Kinondoni farmers. Similar study by Katakweba et al. (2012) conducted in Kinondoni and Morogoro, involved 160 livestock keepers shown the most commonly used antibiotics were oxytetracyline (used by 62.9\% of farmers), sulphadimidine (used by $23.2 \%$ ), streptomycin-penicillin (used by $13.4 \%$ ) and gentamycin (used by $1 \%)$. The results of this study are not inline of our study, because in Katakweba et al. (2012) findings only half of the livestock keepers obtained antibiotics for animal treatments with veterinary prescription and the remaining antibiotics were supplied from the dispensary without any prescription and were dispensed by untrained personnel. Furthermore livestock keepers also changed the antibiotics without consulting veterinarians once they thought the former antibiotics used were not effective; over and above they also used indigenous herbs. Another cross sectional survey at Naogaon district of Bangladesh showed mostly used antibiotics in goats were sulfa drugs (34\%), aminoglycosides (29\%), oxytetracycline (13\%), combination of aminoglycoside and $\beta$ lactamase (12.44\%) and $\beta$ lactamase (10\%) (Sarker et al., 2016). However, this study findings differ with our study because Sarker et al. (2016) study was done in an area where PPR was more prevalent and in Chittagong myiasis is common. Another study of veterinary practices in Switzerland revealed penicillin's and cephalosporin's were the most frequently prescribed antibiotics (37\%), followed by aminoglycosides $(18 \%)$, tetracycline $(14 \%)$ and sulfonamides (11\%) (Regula et al., 2009); compared to this study our study evidenced less amount of penicillin (7.33\%), aminoglycoside (2.20\%), oxytetracycline (6.47\%) and slightly high amount of sulfa drugs (13.95\%). A teaching veterinary hospital based study in Usmanu Danfodiyo University (UDUVTH), Sokoto showed that oxytertracycline was the most commonly used (37.6\%) antibiotic, followed by penicillins (24\%) and aminoglycosides (17.6\%) (Agaie et al., 2016); which is not matched with our findings, possible reason could be the different geographical location and the broad spectrum nature of oxytetracycline, availability and for its wide range of uses. In our study mostly prescribed antibiotic was found streptomycin-penicillin, due to it works against both gram positive and gram negative bacteria and it's wide availability in the local markets and comparatively cheap price than other antibiotics. The second mostly used drug sulfadimidine normally used to treat PPR in goat at TVH. Then amoxicillin also used very commonly to treat fever, respiratory disease in goats. Tylosin used only very less number of patient [7 (0.49\%)] due to it only used in chronic respiratory infection associated with mycoplasma. 


\section{P. Bhowmik and others}

Interestingly, in Bangladesh, vets rarely follow any protocol for identification of the pathogens and its sensitivity to the drug before antibiotics is prescribed. In a study of prescription pattern of the private human practitioners of Dhaka city, antibiotics were prescribed in 70\% of the prescriptions (Begum et al., 2013) and in another similar study, antibiotics were prescribed in $72 \%$ of the instants. In another population-based study in the rural areas of Dhaka and Rajshahi divisions of Bangladesh during July to December 2012, around 44\% physicians prescribed antibiotics in cold and fever before confirmed diagnosis. According to the physicians, patient non-compliance was the main cause of antibiotic resistance in the country $(68.8 \%)$ and more than 50\% patients were found to stop taking the antibiotic as soon as the symptoms disappeared, while only $25.2 \%$ patient completed the full course (Ahmed, 2014). A study in human medicine shows that the highest prescribed antibiotic groups were cephalosporins (31.78\%), macrolides (27.33\%), quinolones (16.33\%), penicillins $(7.11 \%)$, and metronidazoles $(6.78 \%)$ respectively. Two or more antibiotics were prescribed in $25.44 \%$ of prescriptions. A total of $66.89 \%$ prescriptions had complete information on dosage form, $57 \%$ had complete direction for antibiotics use and $64.22 \%$ patients completed full course of antibiotics. Although $83 \%$ prescriptions have no clinical test for using antibiotics (Biswas et al., 2014).

\section{Possible causes of indiscriminate use of antibiotic}

The availability and affordability of good quality antibiotic along with their rational use is needed for effective health care. However, irrational drug use is prevalent, especially in the developing countries (Lalan et al., 2012). A study in New Zealand shown among 22 dairy farmers the most common primary reason for choosing an antimicrobial was veterinary advice $(87 \%)$ followed by personal experience $(68 \%)$. Farmers had limited knowledge or concern about the risk of antibiotic resistance would increase the risk of resistance in their herd and in humans, respectively (McDougall et al., 2017). A Dutch study identified that veterinarians face many conflicting interests when prescribing antimicrobials, including an obligation to alleviate animal suffering, financial dependency on clients, risk avoidance, public health interests and personal beliefs (Speksnijder et al., 2015). Most prescriptions contained either one single antimicrobial substance or a combination of two antimicrobials that complement each other (Regula et al., 2009). However, more than 500 prescriptions of a triple combination of sulphonamide, tetracycline and a macrolide were observed, which is likely to select for multidrug-resistant bacteria (Bischoff et al., 2005; Matter et al., 2007). Another study on prescription pattern in Switzerland shown the largest number of treatments with a dosage above two times the recommended maximum dose in sheep and goats, where group treatment is common (Regula et al., 2009).

\section{Anthropological view of goat owners'}

This is the first survey of farmers' attitudes and beliefs about antimicrobial usage and resistance in Bangladesh. In our survey only $24 \%$ farmers' were familiar with the term "antibiotic", however a survey on French farmers found that only 53\% understood that treatment with antimicrobials was specifically for bacterial diseases (Dernburg et al., 2007). Furthermore, our study evidenced that $100 \%$ farmer had no idea about antimicrobial resistance and withdrawal period of antibiotics, whereas a study in New Zealand showed the majority (79\%) of farmers understood that there is a risk of developing antimicrobial resistance (McDougall et al., 2017) here is far variation of these findings with our, because only $47 \%$ farmer's knowledge had at primary education level and $40 \%$ farmers were illiterate. A study in South Carolina showed that over $40 \%$ of farmers were very familiar with antibiotic resistance and were confident in their use of antibiotics and their participants had high school $(42.9 \%, n=18)$ or undergraduate college $(45.2 \%, n=19)$ education (Friedman et al., 2007).

Personal experience of veterinarian is one of the key of antimicrobial use (McDougall et al., 2017) also farmer's experience of rearing of goat help themselves to know about antibiotics used for the treatment of goat and their withdrawal period. In our study, farmers' experience on average rearing of goat was 40.91 months. Minimum time of rearing goat was 1 month and maximum time was 140 months. The farmer who had longer goat rearing experience known some information about antibiotic than rest of the farmers. Because in this long duration when goat became sick they come to hospital or called private doctor and subsequently known about the term antibiotic. It especially happened for owners who have had at least primary educational background. In human medicine, it is believed that increasing the knowledge and awareness of parents and physicians are key components of prudent use (Bauchner et al., 1999). Hence, changes in prescribing pattern and interaction with farmers will help to change the condition. 
Antimicrobials prescription pattern in goat patients

\section{Therapeutic cost analysis}

Antibiotic resistance is an economic burden on the healthcare system. Resistant infections not only cost more to treat, but also can prolong healthcare use. In a study of attributable medical costs for antibiotic resistant infections, it was estimated that infections in 188 patients from a single healthcare institution cost between $\$ 13.35$ and $\$ 18.75$ million dollars (Roberts et al., 2009). Unfortunately, infections caused by antibiotic resistant bacteria are an everyday occurrence in healthcare settings. Overall, the economic burden associated with AMR is considerable and there is more extensive data than in 2004 . These costs are primarily due to the doubled increase in hospital length of stay, additional discharge costs to facilities, extra medical care needed and productivity loss (WHO, 2007).

Organization for Economic Co-operation and Development (OECD) report indicated that the costs of withdrawing antimicrobial growth promoters in India would be roughly US $\$ 1.1$ billion (Laxminarayan and Chaudhury, 2016). In 2010, China was the largest antimicrobial consumer for livestock, and we estimate that its livestock industry will use up to $30 \%$ of the global antimicrobial production by 2030 . In our study the highest expenditure of antibiotic therapy for gentamicine-sulfadiazine-trimithoprime was $968.18 \mathrm{USD} / \mathrm{annum}$, followed by streptomycin-penicillin 352.06 USD and the lowest expenditure was 5.37 USD/annum for tylosin.

\section{CONCLUSION}

The study provides an overall antibiotic prescription patterns by the hospital based veterinarian. The most commonly used antibiotic in goats was streptomycin-penicillin. We found goat farmers' have zero knowledge on antibiotic resistance and withdrawal period. Therapeutic costs for treating infectious diseases were pretty high. Many of the livestock keepers had no concept on antimicrobial effect on animal body and did not know that: the use of antibiotics could have effects on health of their animals and their own. Therefore, farmers' training and approachable behavior of vet to the farmer during prescription could be beneficial. Additionally, rational prescribing of antibiotics after following guidelines and establishment of specific treatment protocol will change the current situation.

\section{ACKNOWLEDGEMENTS}

We would like to thanks Dr. Bhajan Chandra Das, Professor, Department of Medicine \& Surgery, Director of TVH, Chittagong Veterinary and Animal Sciences University to permit us to use hospital record data. We are also grateful to the goat owners for their cooperation.

\section{REFERENCES}

1. Agaie B, Daneji A, Chafe U, Garba H and Ismaila M (2016). Drug use and prescription pattern at the Usmanu Danfodiyo University Veterinary Teaching Hospital (UDUVTH), Sokoto; A ten-year retrospective study (2006-2015). African Journal of Pharmacy and Pharmacology 10: 978-983.

2. AHI, 2005. Animal Pharm Reports. Antibacterials in the Animal Health Industry: Current markets and future prospects. Available at www.pjbpubs.com/pop_report_download.asp?type_toc\&subid_478\&reportid_781.

3. Ahmed S (2014). Informal drug markets and the emerging threat of antibiotic resistance in Bangladesh. Bangladesh Health Scenario, http://syedmasudahmed.blogspot.com/2014/2010/informal-drug-markets-and-emerging.html.

4. Akter SFU, Rani A, Fauzi M, Rathor MY, Aris M, Aznan M, Jabbar M and Mazumder SK (2012). Hospital physicians' drugs prescription adherence to the essential drugs list of Bangladesh. International Journal of Applied Science and Technology 2: 71-75.

5. Allcock S, Young E, Holmes M, Gurdasani D, Dougan G, Sandhu M, Solomon L and Torok M (2017). Antimicrobial resistance in human populations: challenges and opportunities. Global Health, Epidemiology and Genomics 2: e4.

6. Bauchner H, Pelton SI and Klein JO (1999). Parents, physicians, and antibiotic use. Pediatrics 103: 395-401.

7. Begum F, Uddin MR, Islam MSU, Sarker MN, Barman RC and Ali MY (2013). Evaluation of prescribing pattern of the private practitioners in Bangladesh. Faridpur Medical College Journal 7: 51-53.

8. Bischoff KM, White DG, Hume ME, Poole TL and Nisbet DJ (2005). The chloramphenicol resistance gene $\mathrm{cmlA}$ is disseminated on transferable plasmids that confer multiple-drug resistance in swine Escherichia coli. FEMS Microbiology Letters 243: 285-291.

9. Biswas M, Roy DN, Tajmim A, Rajib SS, Hossain M, Farzana F and Yasmen N (2014). Prescription antibiotics for outpatients in Bangladesh: a cross-sectional health survey conducted in three cities. Annals of Clinical Microbiology and Antimicrobials 13: 15.

10. Costelloe C, Metcalfe C, Lovering A, Mant D and Hay AD (2010). Effect of antibiotic prescribing in primary care on antimicrobial resistance in individual patients: systematic review and meta-analysis. BMJ 340: c2096. 


\section{P. Bhowmik and others}

11. Dernburg A, Fabre J, Philippe S, Sulpice P and Calavas D (2007). A study of the knowledge, attitudes, and behaviors of French dairy farmers toward the farm register. Journal of Dairy Science 90: 1767-1774.

12. Falzon D, Jaramillo E, Schünemann H, Arentz M, Bauer M, Bayona J, Blanc L, Caminero J, Daley C and Duncombe C (2011). WHO guidelines for the programmatic management of drug-resistant tuberculosis: 2011 update. European Respiratory Society.

13. Friedman D, Kanwat C, Headrick M, Patterson N, Neely J and Smith L (2007). Importance of prudent antibiotic use on dairy farms in South Carolina: a pilot project on farmers' knowledge, attitudes and practices. Zoonoses and Public Health 54: 366-375.

14. Hassan MM, Amin KB, Ahaduzzaman M, Alam M, Faruk M and Uddin I (2014). Antimicrobial resistance pattern against E. coli and Salmonella in layer poultry. Research Journal for Veterinar Practitioners 2: 30-35.

15. Katakweba A, Mtambo M, Olsen JE and Muhairwa A (2012). Awareness of human health risks associated with the use of antibiotics among livestock keepers and factors that contribute to selection of antibiotic resistance bacteria within livestock in Tanzania. Livestock Research for Rural Development 24: 170.

16. Kurwijila L, Mwingira J, Karimuribo E, Shirima G, Lema B, Ryoba R and Kilima B (2011). Safety of Animal Source Foods in Tanzania: A Situational Analysis. prepared for the Safe Food, Fair Food Project International Livestock Research Institute Nairobi, Kenya.

17. Lalan BK, Hiray R and Ghongane B (2012). Drug prescription pattern of outpatients in a tertiary care teaching hospital in Maharashtra. International Journal of Pharmacy and Biological Sciences 3: 225-229.

18. Laxminarayan R and Chaudhury RR (2016). Antibiotic resistance in India: drivers and opportunities for action. PLoS Medicine 13: e1001974.

19. Mathew AG, Cissell R and Liamthong S (2007). Antibiotic resistance in bacteria associated with food animals: a United States perspective of livestock production. Foodborne Pathogens and Disease 4: 115-133.

20. Matter D, Rossano A, Limat S, Vorlet-Fawer L, Brodard I and Perreten V (2007). Antimicrobial resistance profile of Actinobacillus pleuropneumoniae and Actinobacillus porcitonsillarum. Veterinary Microbiology 122: 146-156.

21. McDougall S, Compton $\mathrm{C}$ and Botha $\mathrm{N}$ (2017). Factors influencing antimicrobial prescribing by veterinarians and usage by dairy farmers in New Zealand. New Zealand Veterinary Journal 65: 84-92.

22. Mellon M, Benbrook C and Benbrook L (2001). Hogging it. Estimates of antimicrobial abuse in livestock. http://www.ucsusa.org/food_and_agriculture/our-failing-food-system/industrial-agriculture/hogging-it-estimatesof.html\#.WgFQ5FuCzIU

23. Midenge BY (2010). Awareness on recommended veterinary drugs withdrawal periods among small scale dairy cattle farmers in Kinondoni municipality. Muhimbili University of Health and Allied Sciences.

24. Page S and Gautier P (2012). Use of antimicrobial agents in livestock. Revue Scientifique et Technique-OIE 31: 145.

25. Regula G, Torriani K, Gassner B, Stucki F and Müntener CR (2009). Prescription patterns of antimicrobials in veterinary practices in Switzerland. Journal of Antimicrobial Chemotherapy 63: 805-811.

26. Roberts RR, Hota B, Ahmad I, Scott RD, Foster SD, Abbasi F, Schabowski S, Kampe LM, Ciavarella GG and Supino M (2009). Hospital and societal costs of antimicrobial-resistant infections in a Chicago teaching hospital: implications for antibiotic stewardship. Clinical Infectious Diseases 49: 1175-1184.

27. Sarker M, Ahaduzzaman M, Ghosh S and Bary M (2016). Cross-Sectional Survey on Prescribing Patterns for Food Animal Medications in Bangladesh. Journal of Dairy, Veterinary and Animal Research 3: 00089.

28. Sarmah AK, Meyer MT and Boxall AB (2006). A global perspective on the use, sales, exposure pathways, occurrence, fate and effects of veterinary antibiotics (VAs) in the environment. Chemosphere 65: 725-759.

29. Speksnijder D, Jaarsma A, Gugten A, Verheij T and Wagenaar J (2015). Determinants associated with veterinary antimicrobial prescribing in farm animals in the Netherlands: a qualitative study. Zoonoses and Public Health 62: 39-51.

30. Sultana F, Rahman A, Paul TR, Sarwar MS, Islam MAU and Rashid M (2015). Prescribing pattern and prescription errors: a study at a tertiary care hospital of Bangladesh. Bangladesh Pharmaceutical Journal 18: 20-24.

31. Ungemach FR, Müller-Bahrdt D and Abraham G (2006). Guidelines for prudent use of antimicrobials and their implications on antibiotic usage in veterinary medicine. International Journal of Medical Microbiology 296: 33-38.

32. Vaarst M, Paarup-Laursen B, Houe H, Fossing C and Andersen H (2002). Farmers' choice of medical treatment of mastitis in Danish dairy herds based on qualitative research interviews. Journal of Dairy Science 85: 992-1001.

33. Van Boeckel TP, Brower C, Gilbert M, Grenfell BT, Levin SA, Robinson TP, Teillant A and Laxminarayan R (2015). Global trends in antimicrobial use in food animals. Proceedings of the National Academy of Sciences 112: 5649-5654.

34. Van der Fels-Klerx H, Puister-Jansen L, Van Asselt E and Burgers S (2011). Farm factors associated with the use of antibiotics in pig production. Journal of Animal Science 89: 1922-1929.

35. WHO (2007). The world health report 2007: a safer future: global public health security in the 21st century.

36. WHO (2014). Antimicrobial resistance: global report on surveillance. World Health Organization. 